\title{
"HABITANTES DO ARROIO": ESTUDO DE CONFLITOS DE USO DE ÁGUAS URBANAS, RISCO E VULNERABILIDADE EM PORTO ALEGRE-RS
}

\author{
Ana Paula Marcante Soares ${ }^{1}$
}

\section{Introdução}

Para o caso deste ensaio proponho apresentar algumas experiências etnográficas de campo com o objetivo de refletir sobre práticas e representações sociais de meio ambiente e seus respectivos "usos" engendradas por diferentes indivíduos e/ou grupos sociais, em um contexto urbano, em face de situações de risco e vulnerabilidade.

As experiências apresentadas e os questionamentos e reflexões propostos a partir delas estão situadas no âmbito do Projeto de Pesquisa e Ação denominado "Habitantes do Arroio: estudo de conflitos de uso de águas urbanas, risco, saúde pública e comunidades étnicas em Porto Alegre-RS". ${ }^{2}$ O projeto obteve financiamento do CNPq e é desenvolvido conjuntamente por pesquisadores que integram o grupo de pesquisa Banco de Imagens e Efeitos Visuais (Laboratório de Antropologia Social PPGAS/UFRGS) e pela ong Instituto Anthropos.

O projeto "Habitantes do Arroio", iniciado em janeiro de 2009 e finalizado em setembro de 2010, propõe investigar situações de conflito e interdependência entre diferentes grupos sociais, instituições e técnicos da área ambiental envolvidos cotidianamente com os usos (e abusos) das águas do Arroio Dilúvio, em Porto Alegre, Rio Grande do Sul, Brasil. ${ }^{3}$ A prática da pesquisa de campo etnográfica empregada pela equipe do projeto, ao longo do seu desenvolvimento, se constitui na utilização de técnicas de pesquisa da antropologia visual e da técnica de observação participante, a partir do que Eckert e Rocha (Rocha; Eckert, 2003) conceituam como "etnografia de rua".

\footnotetext{
${ }^{1}$ Programa de Pós-Graduação em Antropologia Social da Universidade Federal do Rio Grande do Sul.

2 Anterior a inserção no Projeto desenvolvi a dissertação de mestrado na área de Direito ambiental (CPGD/UFSC) propondo uma reflexão sobre as representações sociais de risco ambiental e sua aceitabilidade pelos diferentes indivíduos e/ou grupos sociais em um conflito "judicializado", o caso do conflito envolvendo a construção de um complexo turístico e de um campo de golfe no município de Florianópolis, no Estado de Santa Catarina.

3 Os resultados da pesquisa podem ser acompanhados através do Blog http://habitantesdoarroio.blogspot.com/ e DVD interativo/Documentário etnográfico "Habitantes do Arroio".
} 
Dessa forma, o projeto proporcionou meu engajamento em processos que permitiram uma iniciação na aprendizagem dos procedimentos e técnicas oriundos do campo da pesquisa antropológica, no mundo urbano contemporâneo, a partir da minha inserção em campo, com a equipe de trabalho, junto aos moradores e freqüentadores da região pesquisada, em torno do Arroio Dilúvio, bem como o diálogo com os técnicos envolvidos nas ações de gerenciamento dos "usos" das águas em questão.

De testemunhos, depoimentos e as observações que daí resultaram, seguindo o recorte teórico-conceitual que fundamenta os problemas propostos pelo projeto de pesquisa, proponho tecer alguns questionamentos sobre os sistemas de práticas e valores que entram em jogo no caso dos conflitos envolvendo as águas num contexto urbano, no caso a sub-bacia do Arroio Dilúvio, em Porto Alegre, e que passam a ser pensados como fenômenos que integram o embate simbólico em que estão referidas as representações de meio ambiente, risco e vulnerabilidade de indivíduos e grupos sociais distintos.

Num contexto de modernas sociedades complexas, sob a perspectiva da forma conflitiva da vida social de Simmel (Simmel, 2004), opera-se com os instrumentos conceituais de trajetória social, práticas e representações sociais para pensar os questionamentos propostos sobre a dinâmica social dos grupos e suas relações com o meio ambiente e seus respectivos "usos", com enfoque no tema do risco e vulnerabilidade.

\section{O ambiente urbano de Porto Alegre e o Arroio Dilúvio: universo de} pesquisa e espaço de problemas

Refletir a "questão ambiental", especialmente os "usos" de águas urbanas e os fenômenos sociais referidos aos mesmos, implica pensar campos de negociação da realidade em planos diversos, entre diferentes indivíduos e/ou grupos sociais, os quais são tencionados por descontinuidades referidas às situações de risco e vulnerabilidade experienciadas por eles.

Para pensar o tema de risco e vulnerabilidade (Douglas, 1996) implicado nos "usos" de águas urbanas proponho apresentar experiências etnográficas de campo compartilhadas ao longo do Projeto, centrando o olhar para alguns testemunhos de "habitantes do Arroio" que relatam experiências de descontinuidades na sua vida cotidiana, indivíduos esses que experienciam situações de vulnerabilidade nas suas práticas referidas aos "usos" do Arroio Dilúvio. 
A proposta é a partir de alguns testemunhos daqueles por nós denominados de "habitantes do arroio" e das observações tecidas sobre suas vidas, conforme propõe Velho (Velho, 1986), pensar esse sujeito no mundo. Quais são as pistas que estes sujeitos fornecem para tecer questionamentos acerca das representações simbólicas, visão de mundo, estilo de vida de populações que habitam a sub-bacia do Arroio Dilúvio? O que essas pistas sugerem em termos de diferenças sócio-culturais significativas que possam indicar práticas singulares em relação aos "usos" do ambiente em questão em face de situações de vulnerabilidade? A partir dessas indicações pretendo sugerir algumas reflexões sobre a complexidade das práticas sociais cotidianamente engendradas por indivíduos e grupos sociais em face de situações de risco e vulnerabilidade num contexto urbano como o Arroio Dilúvio, em Porto Alegre/RS tendo em vista suas trajetórias e itinerários na cidade.

Para tecer tais questionamentos escolho dois interlocutores da pesquisa, "habitantes do arroio", e que, como conjunto, constituem, juntamente com outros, o universo de pesquisa para fins desse ensaio. A partir das situações compartilhadas, em campo, com eles, conformo o espaço de problemas aqui proposto. Ambos os interlocutores da pesquisa vivem em áreas urbanas marcadas pela presença das classes trabalhadoras urbanas (Duarte, 1986), residem em bairros marcadamente originários de ocupações irregulares em termos de moradia e ocupação do solo urbano.

Inserida nesse universo, destacando o tema do risco e vulnerabilidade e seus conteúdos específicos, me aproprio de dois personagens centrais: "habitantes do arroio", moradores de duas regiões específicas do Bairro Agronomia, os quais vivenciam, cotidianamente, situações de risco e vulnerabilidade similares uma vez que tem sua morada construída às margens de dois afluentes do arroio Dilúvio.

O Bairro Agronomia tem seus limites atravessados pelos afluentes da sub-bacia do Arroio Dilúvio, um fenômeno que não lhe é singular uma vez que essa mesma situação se apresenta em outros bairros da cidade de Porto Alegre/RS, tais como Santana, Partenon, Petrópolis, entre outros. A sub-bacia do arroio Dilúvio, hoje marcado pela presença da Avenida Ipiranga, resultado da canalização de suas águas, é o arroio mais importante de Porto Alegre, correspondendo a uma área densamente 
habitada da cidade que representa cerca de um terço da população total da cidade (Menegat, 1998). ${ }^{4}$

O arroio Dilúvio é o principal curso de água da cidade de Porto Alegre e se situa numa região cercada por uma cadeia de morros pelos quais outros arroios da cidade os atravessam, desaguando no arroio em questão. Sua ocupação urbana foi se consolidando no sentido da jusante (centro da cidade de Porto Alegre) para a montante (finalizando na divisa da cidade de Porto Alegre com a cidade de Viamão).

Do ponto de vista técnico de ocupação do solo urbano no entorno da micro-bacia do Arroio Dilúvio, na área central a taxa de impermeabilização do solo atinge grande parte da totalidade de seu curso enquanto nas cabeceiras do arroio e seus principais afluentes (Moinho, Mato Grosso e Carvalho) a taxa de impermeabilização é muito menor, sendo que em alguns locais sua apropriação ainda tem as marcas de um uso rural do solo (Collischonn, Semmelmann e Rochenbach, 2001).

Em relação às demais sub-bacias da cidade, vale ressaltar que essa sub-bacia detém o percentual mais significativo de redes coletoras de esgotamento sanitário do tipo separador absoluto ${ }^{5}$. O arroio Dilúvio tornou-se, assim, o escoadouro natural das águas pluviais de uma sub-bacia de $83,74 \mathrm{~km} 2$ e receptor das águas servidas ${ }^{6}$ geradas por parte dos 446 mil habitantes que ocupam sua área de drenagem (Morandi, 2010). O Arroio Dilúvio recebe, anualmente, parcela significativa de detritos, produtos da erosão natural e da provocada pelo desmatamento das encostas dos morros, além de entulho e lixo (Menegat, 1998).

Nesse contexto, destaco as imagens de transformação da paisagem urbana da cidade Porto Alegre evocadas pela obra de canalização do Arroio Dilúvio. Estendendose pela Avenida Ipiranga, uma das principais vias da cidade, a partir da retificação proposta pela obra de canalização de seu curso natural ${ }^{7}$, alguns afluentes "desapareceram" sob a cidade e seus canais passaram a integrar o sistema de esgotamento pluvial (Menegat, 1998).

\footnotetext{
${ }^{4}$ Estão disponíveis algumas informações sobre o Arroio Dilúvio, pesquisadas no Atlas ambiental de Porto Alegre, no Blog do "Habitantes do Arroio", antes referido, assim como mapas da morfologia da subbacia, de mesma fonte bibliográfica.

${ }^{5}$ A característica principal desse tipo de rede é ser constituída de uma rede coletora de esgotos sanitários e uma outra exclusiva para águas pluviais (águas da chuva). In:Almeida, R. et.al., 2007.

${ }^{6}$ Águas servidas são aquelas manuseadas no cotidiano das habitações para tarefas caseiras. In: Menegat, 1998.

${ }^{7} \mathrm{O}$ Blog do Projeto, além de apresentar a proposta teórico-metodológica, refletindo sobre os dados levantados até então, traz em suas postagens crônicas em vídeo e texto e imagens fotográficas de acervo sobre a cidade de Porto Alegre e o Arroio Dilúvio antes da obra de retificação, iniciada na década de 40, e ao longo da realização da mesma.
} 
Ao situá-lo num contexto urbano contemporâneo, no qual os "usos" das águas correspondem a fenômenos significativos da "questão ambiental", o Arroio Dilúvio e o processo de ocupação urbana do seu entorno representam muitas das contradições possíveis de serem observadas nas grandes metrópoles: o fluxo de pessoas, o lixo acumulado, o fluxo cada vez mais intenso de trânsito, moradores de rua, ocupações irregulares, as zonas residenciais, os bairros "nobres" e condomínios verticais, as "vilas" populares, as zonas comerciais, de serviços e varejo.

Pensar esse cenário do ponto de vista do risco e vulnerabilidade (Douglas, 1996), e situar os conflitos socioambientais que engendram novas concepções espaciais como as bacias hidrográficas ${ }^{8}$, nas quais se insere o Arroio Dilúvio e seu entorno, permite complexificar esse novo arranjo territorial do ambiente urbano. O contexto urbano no qual se insere o Arroio Dilúvio pensado desde a perspectiva das bacias hidrográficas não privilegia apenas sua dinâmica hídrica, mas, sobretudo, seus territórios sobrepostos, em que se expressam diversidades socioculturais que atravessam fronteiras reais e simbólicas e se inter-relacionam conflitivamente.

Ao evocar essas imagens proponho pensar o ambiente urbano da cidade de Porto Alegre em que o viver contemporâneo é marcado pelo conflito, nas suas tensões e contradições, observadas entre os diferentes territórios referidos aos vínculos sociais e simbólicos que os diversos grupos sociais mantêm com seus respectivos ambientes (Little, 2002). O meio ambiente aqui entendido como espaço simbolicamente vivido e representado no qual estão colocadas as fronteiras reais e simbólicas pelas quais transitam diferentes redes de relações e situados domínios diversos da vida cotidiana (Devos, 2007).

\section{A casa no Arroio, o Arroio na casa: práticas e representações sociais de}

\section{"habitantes do Arroio" em face de situações de vulnerabilidade}

Pensar o meio ambiente como um espaço simbolicamente vivido e representado em que estão colocadas as fronteiras simbólicas pelas quais transitam diferentes redes de relações sociais e onde estão situados domínios diversos da vida cotidiana (Devos, 2007) significa situá-lo no interior de processos da vida social onde estão presentes formas de negociação com o meio cósmico. O desafio que se coloca é pensá-lo segundo suas diferentes escalas interpretativas, considerando-se os estilos de vida e visão de

\footnotetext{
${ }^{8}$ A bacia hidrográfica considera a complexidade da malha hídrica para pensar um "recorte" territorial urbano.
} 
mundo de indivíduos e grupos sociais que com ele interagem em suas vidas cotidianas (Velho, 2004).

Na sub-bacia do Arroio Dilúvio, portanto, encontramos ao longo da pesquisa com moradores de bairros "nobres" da cidade tanto quanto os habitantes das "vilas" populares e os trabalhadores atuantes nas áreas de comércio e de prestação de serviços que se distribuem ao longo de sua extensão, dos mais próximos aos mais distantes da sua área de canalização, além dos técnicos que atuam na gestão das águas da microbacia em questão. Em termos etnográficos, encontramos a coexistência de realidades sociais diversas delineadas numa dimensão conflitiva (Simmel, 2004) em termos dos usos de suas águas.

Assim, proponho refletir a partir dos itinerários urbanos expressos nas trajetórias sociais (Velho, 2004) de "habitantes do arroio" como forma de pensar o arranjo da vida no tempo e no espaço a partir da experiência de alguns narradores/interlocutores da pesquisa.

\section{O cenário dos conflitos de usos de águas urbanas}

A escolha sobre a apresentação de duas situações de usos das águas do Arroio Dilúvio nos permite pensar os estilos de vida e visões de mundo como dimensões significativas para a interpretação dos sentidos das categorias risco e vulnerabilidade em suas práticas sociais no que se refere aos "usos" do ambiente (Eckert; Rocha, 2005).

Referimo-nos aqui as alterações das bacias urbanas a partir de loteamentos e ocupações regulares ou irregulares que resultam em impermeabilização do solo, na degradação das margens de arroios pela erosão das áreas de baixo declive, no depósito de resíduos oriundos das áreas de alto declive, na ausência de saneamento, na retirada da vegetação próxima às áreas de mata ciliar e na desestruturação da camada superficial do solo, na movimentação de volumes de terra, no despejo de poluentes, etc., um fenômeno que durante os períodos de cheias tem provocado grandes inundações.

A primeira situação etnográfica que apresento é o depoimento de Senhor Detamar, morador do Beco dos Marianos, no Bairro Agronomia, próximo a Faculdade de Agronomia da Universidade Federal do Rio Grande do Sul. Nesse trecho do Arroio Dilúvio, a obra de canalização não mais possui os taludes de contenção, mas, sim, uma vegetação que toma conta daquele espaço onde corre a água do arroio, dando um aspecto mais natural ao seu percurso. 
A área onde se situa a residência do Senhor Detamar, ainda que sem pavimentação, possui obras de infra-estrutura urbana tais como coleta de lixo, abastecimento de água, energia elétrica, sendo atendida por um sistema de transporte próximo a uma grande via de intenso fluxo. Entretanto, como pude observar na primeira oportunidade em que estive lá junto com a equipe de trabalho do projeto ${ }^{9}$ trata-se de uma área de ocupação urbana irregular que tende a se expandir para as encostas do morro Santana, área considerada como área de preservação permanente. ${ }^{10}$

A região denominada de Beco dos Marianos reúne uma população que tem sua moradia instalada em locais sem saneamento básico, onde dificilmente passa o Departamento Municipal de Limpeza Urbana (DMLU) para a coleta de lixo, sendo que as casas ocupam uma área de grande declive do morro próximo a uma extensa área verde não edificada. $\mathrm{O}$ tipo de moradia varia desde casas populares simples de alvenaria a casas mais precárias, construídas com madeiras e outros materiais, em torno das quais se podem observar depósito de resíduos sólidos (garrafas e sacos de plásticos, entre outros materiais).

Na parte "baixa" do morro, próximo as áreas de drenagem da águas de um dos afluentes do Arroio Dilúvio, os moradores costumam construir contenções feitas com pneus velhos, os quais durante as cheias são levados para dentro do arroio, ocasionando depósito de sedimentos ao longo de toda a sua extensão, chegando até mesmo a sua foz, no Lago Guaíba. Essa população, em sua maioria, não está ligada a rede pública de esgotos, não sendo atingidas pelo sistema de escoamento de águas pluviais nem pelo sistema de esgotamento sanitário. Esse cenário remete a uma das categorias com as quais o projeto se propôs pensar o meio ambiente urbano de Porto Alegre, através do Arroio Dilúvio: a vulnerabilidade e o risco ambiental (Douglas, 1996).

\footnotetext{
9 Estivemos, em equipe, para gravar imagens de uma obra de saneamento, realizar entrevistas com informantes, visita com o grupo que nos acompanhou num percurso realizado por uma ação do projeto ("Percursos Urbanos", disponível em: http://habitantesdoarroio.blogspot.com/2009/12/percursos-2.html).

${ }^{10}$ Em termos do que se entende por "ocupação irregular" em um contexto urbano, ocupação urbana de áreas sujeitas à limitações ou vedações, pelo Poder Público, as encostas de morro representam, em termos técnicos, "áreas de risco geológico". Eventos como rolagem de rochas, chuva, desmatamento, depósitos clandestinos de lixo, escorregamento do solo com material rochoso devido à ação da água somada à declividade do morro, as fossas sanitárias, o alagamento de áreas após fortes chuvas, o lançamento inadequado no solo de águas usadas cotidianamente nas tarefas caseiras, a execução inadequada de aterro, a erosão do solo, o desmatamento, entre outros fatores, potencializam a vulnerabilidade dessas "ocupações irregulares" consideradas "áreas de risco" (Menegat, 1998) No Blog do Projeto há uma postagem que disponibiliza um mapa ilustrando todos esses eventos em uma área denominada "Área de Risco Geológico" contido no Atlas Ambiental. Ver em: http://habitantesdoarroio.blogspot.com/2009/03/area-de-risco-geologico-ocupacao-urbana.html
} 
Nesse local, na rua de chão batido que faz o traçado do Arroio Dilúvio até a Avenida Ipiranga, uma importante via de tráfego da cidade, mora o Senhor Detamar. Ele é um homem de meia idade, membro de classe trabalhadora urbana, que reside nas proximidades do Beco há mais de vinte e sete anos, pois seu pai também morou naquela localidade. É casado e tem um filho jovem, entre uns dezoito, vinte anos que, atualmente, segue carreira militar. Trabalha como funcionário público da Universidade Federal do Rio Grande do Sul, da Faculdade de Agronomia, ocupação que lhe propicia condição de vida diversa de grande parte de seus vizinhos, pois reside numa casa relativamente ampla, de alvenaria e bem cuidada, localizada em um extenso terreno.

Em termos de capital intelectual, pela forma como empreende seu discurso, ao relatar suas experiências, e pela própria função de cunho administrativa que exerce como funcionário público, denota ter concluído os estudos escolares tal como propiciou ao seu filho.

O pátio da sua casa é atravessado pelo Arroio que desce o Morro Santana e que vai desaguar dentro do Arroio Dilúvio que está logo à frente ao seu portão, do outro lado da rua de chão batido. O depoimento do Senhor Detamar sobre o arroio que atravessa o terreno da sua casa nos desafia a pensar suas práticas cotidianas em termos de visão de mundo e estilo de vida (Velho, 2004) de modo a refletir sobre o porquê ele se coloca de forma singular em relação aos "usos" daquele ambiente em face das situações de vulnerabilidade experienciadas por ele. Nesse sentido, ele diz:

Esse arroio parece tranqüilo né... tu olha assim fora do periodo de enxurrada ai ele não tem tanta vazão e ai a gente pensa que ele é sempre assim, mas olha, tem periodos ai que te assusta. (...) Normalmente eu olho o meu ali como é que está e ali para cima também. Já entrei várias vezes ali para tirar material, isso eu faço... (...) Sou obrigado a manter, se eu não fizer isso, é minha segurança, levanta água.

Em outro momento, ao relatar as suas práticas cotidianas de limpar o Arroio morro acima ele refere negociar com os demais moradores, seus vizinhos, para que evitem o despejo de material (ou de lixo) nas águas, evitando, assim, que, em dias de chuva, transborde para as suas próprias casas. Relata algumas articulações que promoveu junto aos órgãos públicos responsáveis por melhorias de infra-estrutura e de saneamento, no bairro onde mora, tais como verificar a coleta de lixo e cobrar o andamento de uma obra de canalização. Além disso, mostrou, nos fundos da casa, para a equipe do projeto que acompanhava a entrevista, como desenvolve, em casa, a técnica 
de compostagem como forma de reaproveitamento de resíduos orgânicos para adubo. Sobre a relação com o lixo que produz diz:

(...) Acho que não precisa nem se preocupar em retirar material é não lança o material ... se tu produz lixo tu também é responsável por ele. Eu acho isso, é essa a minha preocupação, eu faço alguma coisa em beneficio a mim e a comunidade, eu tenho que cuidar daquilo que eu produzo.

Foi a partir desse ponto de vista que passei a me questionar quais as pistas sugeridas pelo Senhor Detamar, em termos de trajetória social (Velho, 2004) são capazes de conformar a singularidade de sua ação preservacionista na área do arroio em relação a outros moradores locais em razão de sua adesão a um estilo de vida e visão de mundo ecológica em relação aos usos daquele ambiente. A identificação das situações de vulnerabilidade e a avaliação das condições de risco são aqui reveladoras de sua diferença em relação aos seus vizinhos do bairro.

Sob essa perspectiva, tecer questionamentos sobre as suas práticas cotidianas engendradas em face de uma situação de vulnerabilidade e risco pode ser sugerido a partir da noção de visão de mundo e estilo de vida (Velho, 2004) construída em função de experiências sócio-culturais próprias a trajetória do Seu Detamar e de sua família de origem no lugar. Uma trajetória de classe trabalhadora vivida por sua família na região e que, provavelmente, se diferencia da experiência geracional do Senhor Detamar em relação aos seus pais. Sua inserção de trabalho no contexto universitário, sua proximidade com outras experiências sociais, marcam diferenças a realidade vivida hoje pelas classes trabalhadoras que migraram recentemente para essa região da cidade e vem ocupando de forma irregular as encostas do morro. A condição de trabalho e de perifização de sua família de origem se distancia daquela vivida por outras famílias na região tanto quanto as condições de ocupação do Morro Santana da época de seus pais e dos seus vizinhos mais recentes não são as mesmas.

Importante frisar que, em relação à perifização e ao processo de ocupação do bairro, embora a sua casa esteja, hoje, localizada em uma área de ocupação irregular, essa irregularidade se legitima até certa medida, em razão de ter sido permitida pela própria Universidade Federal, proprietária da mesma. Essa situação de legitimidade de morar numa área de uso público tece algumas fronteiras simbólicas entre moradores antigos dessa parte do bairro Agronomia, próxima ao morro Santana, e os moradores que para ali se dirigem como resultado de processos de ocupação recente, cujas 
condições precárias de moradia os torna mais facilmente identificados como irregulares.

A legitimidade dos moradores mais antigos do Beco dos Marianos se deve ao fato de serem, boa parte, funcionários ou ex-funcionários da Universidade Federal do Rio Grande do Sul e exercer essas funções os permitiu morar naquele local, na época em que foi ocupada, permanecendo lá desde então. O pai do Senhor Detamar era funcionário da Universidade Federal, assim como o seu filho, reforçando-se, assim, o seu pertencimento a uma rede social de ex-funcionários e funcionários que ali residem, os quais foram indicados aos cargos na instituição, em função de uma rede de relações e de parentesco que se teciam no interior do trabalho. Boa parte de seus moradores mais antigos são funcionários públicos e entram para trabalhar na Universidade Federal numa época em que não havia concurso público.

Vale ressaltar, que próximo ao Beco dos Marianos, também nos limites finais da Avenida Ipiranga, no Morro Santana, temos ainda uma outra comunidade de trabalho mais antiga formada por trabalhadores da CEEE, Companhia Estadual de Energia Elétrica do Estado do Rio Grande do Sul, cujos vínculos com a empresa pública se tecem da mesma forma que a descrita para o caso dos funcionários da Universidade Federal.

Portanto, pensar o processo de ocupação do Beco dos Marianos, no Bairro Agronomia, inserido num contexto urbano de Porto Alegre, como perifização e ocupação irregular de áreas urbanas, em termos de desigualdade social e segregação espacial das cidades (Caldeira, 2003) acaba por ser dinamizado pelo próprio sentido dado a essa ocupação irregular tida como legítima enquanto provocada, em épocas passadas, pelos funcionários de um órgão público federal ou estadual que residem perto do seu local de trabalho. Isto em relação ao tempo presente, que situa os demais moradores, sem vínculos ou laços com o funcionalismo público estadual ou federal, como uma população vivendo sob condições de vulnerabilidade e, por derivação, sujeitos a uma situação de risco maior que os demais moradores. Uma falsa aparência ao problema. As diferenças singulares do Senhor Detamar em relação aos seus vizinhos, alguns deles seus colegas de trabalho, nos revelam que, num caso (os outsiders, famílias oriundas da ocupação recente das encostas do morro Santana e das margens do arroio) ou em outro caso (os estabelecidos, famílias oriundas da antiga ocupação urbana do bairro, próximas da UFRGS e CEEE), a proximidade com a cultura do funcionalismo público em nada garante a adesão a um estilo de vida e visão de mundo ecológica em 
relação aos usos das águas de um dos afluentes do arroio Dilúvio.

No que concerne à carreira profissional do Senhor Detamar na UFRGS - atuando no setor de informática do Curso de Agronomia, setor de Agroecologia, essa pode ser pensada em termos da sua interação com redes de relações mais amplas e diversificadas, em que o contato com o mundo acadêmico e os saberes técnicos e científicos pode configurar a visão de mundo e estilo de vida de indivíduos situados em camadas sociais particulares, estabelecendo diferenças internas (Velho, 2004). Por um lado, ele relata que foi no seu ambiente de trabalho e das trocas com professores da Faculdade de Agronomia que aprendeu a desenvolver a técnica de compostagem, na sua casa, como forma de reaproveitamento de resíduos orgânicos para adubo, implicando em uma relação diversa com o lixo que produz. Por outro, a sua condição de trabalho, em termos de campo de possibilidades (Velho, 2004) de trajetória de ascensão individual, enquanto funcionário público, possibilitou um estilo de vida mais próximo de camadas médias urbanas, possibilitando pensar que essa mobilidade social é capaz de introduzir variáveis significativas na sua experiência individual.

Nesse sentido, é possível pensar a experiência individual do Senhor Detamar como inserida numa problemática mais ampla do trânsito entre mundos socioculturais diversos, conforme refere Velho ao problematizar o papel de mediadores que certos indivíduos desempenham inseridos num contexto metropolitano (Velho, 2001).

Num contexto urbano, os indivíduos estão potencialmente expostos a experiências muito diferenciadas na medida em que transitam em universos socioculturais distintos, estilos de vida e modos de percepção da realidade também distintos (Velho, 2001: 20). Ainda seguindo G. Velho (2001:20) certos indivíduos mais do que outros não somente fazem esse trânsito como desempenham o papel de mediadores entre diferentes mundos e experiências. Aspecto este que pode ser pensado em relação à forma como Senhor Detamar lida com o ambiente em que vive e o conhecimento que adquire e a negociação com os demais moradores, seus vizinhos, em relação ao lixo que produzem nesse ambiente.

A segunda situação etnográfica que apresento é o depoimento da Senhora Maria Iracema, também moradora do Bairro Agronomia, numa região liminar, próxima à divisa do Município de Porto Alegre com Viamão. O local ao qual me refiro é a Vila Herdeiros, nos arredores da nascente do Arroio Dilúvio, a chamada Barragem do Sabão. A Barragem "Lomba do Sabão" é um reservatório de água utilizado para abastecimento de água de Porto Alegre e corresponde a nascente do Arroio Dilúvio, localizada numa 
unidade de conservação, o Parque Municipal Saint Hilaire, em Viamão. O nome da barragem vem do "Riacho do Sabão" como o arroio Dilúvio era conhecido antes da obra de retificação.

A Vila Herdeiros, localizada nos arredores da barragem, tem sua origem remontada à propriedade de terras pertencente à família Santana que, em razão da herança deixada pelo casal proprietário dessas terras aos seus filhos, herdeiros, portanto, deu nome a Vila. Os herdeiros da família Santana lotearam e venderam os terrenos ou somente as casas aos atuais moradores, inclusive, o terreno onde se localiza a escola pública, é uma doação dos herdeiros dessa família.

A região onde se localiza a Vila Herdeiros, os terrenos loteados, o foram em locais, em sua maioria, que não poderiam ser ocupados por se tratarem de área de risco em razão da proximidade com o arroio e a barragem sujeitos aos deslizamentos e inundações. Além disso, outra tensão que marca esta área é o fato de parte da população da Vila Herdeiros estar assentada dentro da área de preservação permanente, portanto, em termos de irregularidade é marcada para além da questão de risco e vulnerabilidade, mas, também, pela potencialidade de danos ambientais à área protegida.

A principal questão que aparece aqui sobre as moradias e o transcurso da água do arroio Dilúvio, entre as casas, é a do valão. O nome de valão é recorrente em outras regiões da sub-bacia, principalmente na beira de seus afluentes, e não se refere à água que corre no arroio, mas, sim, ao canal pelo qual a água e o esgoto não tratados passam. O risco de inundação é presente na medida em que o valão transborda quando tem muita água para escorrer da barragem em dias de chuvas mais intensas.

Em termos de infra-estrutura urbana os moradores possuem abastecimento de água, rede elétrica, sistema viário, as ruas principais são asfaltadas, coleta de lixo, mas não possuem sistema de tratamento de esgoto sanitário. É possível observar que há algumas casas simples de alvenaria, muradas, outras gradeadas, um pequeno condomínio de casas geminadas, em condições diversas de casas e casebres de madeira sobre palafitas de tijolos feitas pelos moradores. O que as distancia é uma rua asfaltada que separa a margem do arroio, ou do valão, sendo que as casas de alvenaria estão na margem oposta ao arroio e os casebres junto ao transcurso da água. Num cenário marcado por casas que se avizinham e se separam não por ruas, mas pelo transcurso do arroio, as pontes notadamente improvisadas pelos moradores são freqüentes, assim como os sacos de areia para contenção. 
Nesse local, reside a Senhora Maria Iracema. Uma senhora negra de cabelos brancos membro de classe trabalhadora urbana. Ela adquiriu sua casa de madeira, sobre palafitas de tijolos, na beira do arroio Dilúvio, comprando-a por um preço bom, conforme diz, mas sem adquirir o terreno, situação análoga aos demais moradores residente desta região de ocupações irregulares em área mais vulnerável da Vila Herdeiros.

Em termos de risco e vulnerabilidade, fatores como desmatamento de mata ciliar, no em torno do arroio, fossas sanitárias inadequadas, deslizamentos da área em aclive próxima a barragem, depósito de lixo, entre outros, estão visivelmente presente nesse ambiente. A condição de risco e vulnerabilidade em que está colocada a residência da Senhora Maria Iracema é parecida com muitas das casas de seus vizinhos e a presença das inundações constantes, causadas pela cheia da barragem em dias de chuva marcam, não somente a sua fala, mas, também, de outros moradores daquela região.

A partir de outra situação compartilhada, em campo, presenciamos e escutamos estórias de moradores da Vila Herdeiros a partir do olhar de estranhamento sobre a paisagem do arroio de crianças que moram e estudam nessa mesma Vila. Pudemos acompanhar alunos do ensino fundamental envolvidos em uma atividade propiciadas por uma professora de geografia da escola pública da Vila Herdeiros. As crianças mostravam o lixo acumulado no arroio e responsabilizavam seus vizinhos pela sujeira do ambiente, falando em termos de consciência ambiental.

Nesse ponto, é interessante pensarmos que em termos de visão de mundo e estilo de vida (Velho, 2004) de uma criança, como Guilherme, que questionada sobre a utilidade da barragem responde "para destruir a casa dos outros", se, por um lado, a sua família de origem está referida a uma trajetória de classe trabalhadora urbana, vivendo em condições de vida precária, em relação ao tipo de moradia, a sujeição às freqüentes inundações, a ausência de saneamento, etc., situação análoga a da Senhora Iracema, por outro, a sua experiência se diferencia da experiência geracional dos seus pais. A sua inserção em intervenções didáticas promovidas nas aulas de geografia, como no projeto da "Semana do meio Ambiente" que participa, junto com seus colegas, em termos de “ambientalização" (Lopes, 2004) da questão pública do meio ambiente de projetos educacionais, evocando um discurso mais ecológico para pensar as práticas cotidianas suas e dos moradores do lugar onde mora, acarreta uma re significação sobre os usos" do meio ambiente em que ele está inserido. 
As crianças relatam o cotidiano de quem vive na Vila Herdeiros em face de situações de vulnerabilidade e risco em função da barragem e as inundações causadas por ela. As pontes improvisadas pelos próprios moradores, dando acesso aos becos e ruelas, são frequentemente refeitas em razão da destruição causada pelas enchentes em dias de chuvas mais intensas. Nos dias que a água da barragem está baixa os moradores a atravessam a pé para levar as crianças à escola.

O depoimento da Senhora Iracema sobre as freqüentes cheias do arroio que beira o terreno da sua casa com as quais convive nos desafia a pensar em termos de trajetória social (Velho, 2004) e da própria noção de "periferização":

(...) eu pra mim se até fosse um lugar bom, se não tivesse esse riacho ai, até eu gostaria que a pessoa saísse né, que desse outro lugar bom pra pessoa morar, mas não que eu não goste, eu gosto daqui dessa zona, mas as água quando invade né...

A Senhora Maria Iracema, vivendo em condições precárias de vida, em termos de tipo de moradia, permanece naquele lugar sujeito às inundações. Em termos de trajetória social (Velho, 2004) seu depoimento dá pistas que pela condição de trabalho, ou quem sabe mesmo migratória, para escolha da casa em razão de um bom preço, em termos simbólicos dá um sentido outro de pertença ao lugar onde mora. Os processos de intervenção do Poder Público para retirada de parte da população da Vila Herdeiros que vive nas áreas de risco são relatados por ela como tendo sido várias vezes provocados, mas inefetivos, acarretando na permanência dela e de seus vizinhos até hoje.

Portanto, pensar o processo de ocupação da Vila Herdeiros, no Bairro Agronomia, inserido num contexto urbano de Porto Alegre, como ocupação irregular de áreas urbanas se dá em termos de desigualdade social e segregação espacial das cidades (Caldeira, 2003), pois, nesse caso, não há um processo de "legitimação" em termos de ocupação por famílias de origem do lugar, mas um processo de "periferização" da cidade. $^{11}$

Em meio ao complexo processo de ocupação da Vila Herdeiros, há conflitos juridicializados relacionados ao arroio Dilúvio, dentre os quais, a intervenção do Poder Público municipal para retirada de parte da população da Vila assentada dentro da área de preservação permanente, próximo à barragem, devido aos desmoronamentos e inundações. O processo de ocupação da Vila Herdeiros remonta a década de 50, mas o

\footnotetext{
${ }^{11}$ Referem que apesar das limitações formais, algumas áreas próximas às cabeceiras da rede de drenagem vem sendo ocupadas. In: Collischonn, Semmelmann e Rochenbach, 2001.
} 
acréscimo do número de famílias residentes na área de preservação se deu de forma significativa a partir da década de 90 .

Proponho pensar que a questão social referida ao processo de "periferização" em termos de desigualdade social e segregação espacial (Caldeira, 2003) implicado no crescimento do processo de ocupação irregular, nesse período, da vila Herdeiros, e, sobretudo, a questão do risco e vulnerabilidade relacionada às ocupações, se transforma ao ser tratada desde uma perspectiva ambiental, inserido num processo de ambientalização (Lopes, 2007). Essas intervenções formais do Poder Público visando à retirada dessa população da área de preservação ambiental, portanto, inserida num processo de ambientalização (Lopes, 2007) indica a institucionalização da "questão ambiental", no qual a própria concepção do conflito se transforma.

Esse contexto tencionado pelas áreas de risco aqui problematizadas pode ser pensado em termos de uma alteração na forma de pensar e conceber esses eventos críticos, como as cheias, as inundações, a ausência de saneamento das "ocupações irregulares" no arroio Dilúvio. A partir das situações compartilhadas, em campo, junto aos técnicos atuantes na área ambiental, a dinâmica desse processo foi sendo construída como uma das questões para reflexão propostas pelo Projeto "Habitantes do Arroio".

No espaço desse ensaio, problematizar as concepções contemporâneas de risco (Douglas, 1996) e vulnerabilidade, a partir dos itinerários urbanos expressos nas trajetórias sociais dos indivíduos, propõe pensar a forma como a paisagem urbana do Arroio Dilúvio se configura na compreensão da passagem do tempo e do arranjo da vida social expressos nas narrativas desses sujeitos, como a Senhora Maria Iracema e Senhor Detamar.

Pensar quais as pistas eles sugerem em termos de diferenças sócio-culturais significativas que possam indicar práticas singulares em relação aos "usos" do ambiente em face de situações de vulnerabilidade em que estão colocados, provoca refletir sobre o próprio lugar do arroio dilúvio na territorialidade expressa nas narrativas dos interlocutores da pesquisa, "habitantes do arroio". As próprias experiências diferenciadas a que estão expostos na medida em que transitam entre universos distintos, estilos de vida e modo de percepção da realidade também diferenciados ou contrastantes, como no caso desses sujeitos.

A complexidade expressa nessas experiências nos desafiam a pensar como relacionar esses diferentes pontos de vista em relação ao tema do risco e vulnerabilidade, inclusive o ponto de vista do técnico envolvido nessa questão no 
contexto do ambiente urbano da micro-bacia do Arroio Dilúvio, considerando os diferentes territórios sobrepostos, em que se expressam diversas realidades socioculturais e se inter-relacionam desde uma perspectiva conflitiva.

\section{Referências bibliográficas}

ALMEIDA de, Rogério et. al. Indicadores de Riscos Ambientais para os Trabalhadores nos Serviços de Coleta e Tratamento de Esgoto Domiciliar. In:Revista eletrônica Mestrado Educação Ambiental. ISSN 1517-1256, v.18, jan.-jun./2007. pp. 415- 432.

CALDEIRA, T. P. do R. Cidade de muros. São Paulo: Ed. Edusp, 2003.

COLLISCHON, Walter; SEMMELMANN, Franz Rainer; ROCKENBACH, Carlos Alberto. Drenagem urbana e sedimentos: o caso do arroio dilúvio. In: Carlos E. M. Tucci; David da Motta Marques. (Org.). Avaliação e controle da drenagem urbana. Porto Alegre: ABRH, 2001, v. 2, p. 521-548.

DEVOS, Rafael. A Questão Ambiental sob a ótica da antropologia dos grupos urbanos, nas ilhas do Parque Estadual Delta do Jacuí, Bairro Arquipélago, Porto Alegre, RS. Tese de Doutorado. Programa de Pós-Graduação em Antropologia Social/UFRGS, Porto Alegre, 2007.

, ROCHA, A. L. C.; SOARES, A. P. M. ; CARVALHO, L. ; BECK, D.; RIBEIRO, R. Habitantes do Arroio. 2009 (site da internet- Blog).

DOUGLAS, Mary. La aceptabilidad del riesgo según las ciencias sociales. Barcelona: Paidós, 1996.

e WILDAVSKY, Aaron. Risque et Culture. Sociétes. Nº. 77, vol. 3, 2002.

Disponível em: www.cairn.info. Acesso em 26 de setembro de 2006.

DUARTE, Luiz Fernando Dias. Da vida nervosa nas classes trabalhadoras urbanas. Rio de Janeiro: Jorge Zahar Editor/Cnpq, 1986.

ECKERT, Cornelia e ROCHA, Ana Luiza Carvalho da. Etnografia de Rua: Estudo de Antropologia Urbana. In: RUA, Revista do Núcleo de Desenvolvimento da Criatividade da Unicamp - NUDECRI - Campinas, março 2003, número 9. p. 101 a 127.

LITTLE, Paul. Territórios sociais e povos tradicionais no Brasil: por uma antropologia da territorialidade. Série Antropologia. Brasília: UNB, 2002.

LOPES, José Sérgio Leite. Sobre processos de "ambientalização" dos conflitos e sobre dilemas da participação. In: Horizontes Antropológicos. Porto Alegre: PPGAS, jan./jun. 2006, vol.12, $\mathrm{n}^{\mathrm{o}} .25, \mathrm{pp} .31-64$. 
MENEGAT, Rualdo (Coord.). Atlas ambiental de Porto Alegre. Porto Alegre: Ed. Universidade/UFRGS, 1998. pp. 39-40

MORANDI, Iara Conceição; FARIA, Carla Marques. A difícil reparação de arroios em áreas urbanas: arroio dilúvio, Porto Alegre/RS. XXVII Congresso Interamericano de Engenharia Sanitária e Ambiental ABES - Associação Brasileira de Engenharia Sanitária e Ambiental, Recife/PE, 2009. Disponível em: http://www.abes-dn.org.br/

ROCHA, A. L. C. da; ECKERT, C. O tempo e a cidade. Porto Alegre: Editora da UFRGS, 2005.

SIMMEL, G. Philosophie de la Modernité. Paris: Payot, 2004.

SOARES, Ana Paula Marcante. O risco ambiental na sociedade contemporânea: contribuições de uma abordagem cultural. Dissertação de Mestrado. Curso de PósGraduação em Direito da Universidade Federal de Santa Catarina, CPGD-UFSC, 2007.

VELHO, G. Individualismo e Cultura. Notas para uma antropologia da sociedade contemporânea. Rio de Janeiro: Jorge Zahar, 2004.

e KUSCHNIR, K. (Orgs.) Mediação, Cultura e Política. Rio de Janeiro: Aeroplano, 2001. 